University of Nebraska - Lincoln

DigitalCommons@University of Nebraska - Lincoln

Ground Water Recharge and Chemical Contaminants: Challenges in Communicating the Connections and Collisions of Two Disparate Worlds

Christian G. Daughton

U.S. Environmental Protection Agency, daughton.christian@epa.gov

Follow this and additional works at: https://digitalcommons.unl.edu/usepapapers

Daughton, Christian G., "Ground Water Recharge and Chemical Contaminants: Challenges in Communicating the Connections and Collisions of Two Disparate Worlds" (2004). U.S. Environmental Protection Agency Papers. 127.

https://digitalcommons.unl.edu/usepapapers/127

This Article is brought to you for free and open access by the U.S. Environmental Protection Agency at DigitalCommons@University of Nebraska - Lincoln. It has been accepted for inclusion in U.S. Environmental Protection Agency Papers by an authorized administrator of DigitalCommons@University of Nebraska - Lincoln. 


\title{
Ground Water Recharge and Chemical Contaminants: Challenges in Communicating the Connections and Collisions of Two Disparate Worlds
}

\author{
by Christian G. Daughton
}

\begin{abstract}
Our knowledge base regarding the presence and significance of chemicals foreign to the subsurface environment is large and growing-the papers in this volume serving as testament. However, complex questions with few answers surround the unknowns regarding the potential for environmental or human health effects from trace levels of xenobiotics in ground water, especially ground water augmented with treated waste water. Public acceptance for direct or indirect ground water recharge using treated municipal waste water (especially sewage) spans the spectrum from unquestioned embrace to outright rejection. In this paper, I detour around the issues most commonly discussed regarding ground water recharge and instead focus on some of the less-recognized issues--those that emanate from the mysteries created at the many literal and virtual interfaces involved with the subsurface world. My major objective is to catalyze discussion that advances our understanding of the barriers to public acceptance of waste water reuse with its ultimate culmination in direct reuse for drinking. I pose what could be a key question as to whether much of the public's frustration or ambivalence in its decision-making process for accepting, or rejecting, water reuse (for various purposes including personal use) emanates from fundamental inaccuracies, misrepresentation, or oversimplification of what water is and how it functions in the environment - just exactly what the water cycle is. These questions suggest it might behoove us to revisit some very elementary aspects of our science and how we are conveying them to the public.
\end{abstract}

\section{Introduction}

Could a world where "water is worth its very weight in gold" eventually come true? A future world where "a depletion of the earth's water supply has led to a governmentenforced ban on private toilets" and "the privilege to pee is regulated by a single, malevolent corporation, which profits by charging admission for one of mankind's most basic needs" might strike us as pure fantasy. However, this scenario-as created for the Broadway musical Urinetownnonetheless points to the unarguable growing importance of water in sustaining society (Daughton 2003a). Fresh water will play profound roles in the sustainability of water-poor geographic areas such as the western United States (U.S. Department of the Interior 2003).

The major issues surrounding the need to recycle municipal waste water for a wide spectrum of uses (perhaps with the ultimate objective of achieving true, direct recycling of sewage as a dependable source of human drinking water) are discussed in a growing literature too large to easily distill. The barriers to achieving the ultimate goal are many and hide

Published in 2004 by the National Ground Water Association. behind two well-known classes of invisible hazardspathogens and chemicals. Fine overviews and history of waste water reuse, perspectives regarding public concerns, and future research needs are available in countless articles, some representative ones being Asano (2001), Higgins et al. (2002), National Research Council (1998), and U.S. Environmental Protection Agency (EPA) (1992).

Formal regulatory water quality criteria for protecting human health and ecological integrity by minimizing exposure to common pathogens and gross measures of pollution or nuisance were enacted in the United States with the Federal Water Pollution Control Act Amendments of 1972. These criteria evolved to include specific chemical pollutants or pathogens (or suitable surrogates). Conventional waste water and drinking water treatment technologies were designed to cope with gross, combined measures of pollution such as chemical oxygen demand. We must keep in mind that the suite of pollutants historically required by regulation to be monitored were selected when higher quality (native) waters often served as the primary source of drinking waters. With growing populations, the pressure on traditional water resources continues to increase because streams receiving treated waste (and serving as downstream drinking source waters) contain ever higher proportions of treated waste, and 
the influent to, and effluents from, sewage treatment plants carry ever-increasing numbers of new types of chemicals (emerging pollutants). Treatment facilities were never designed to achieve quantitative, stoichiometric removal efficiencies for these individual, unregulated pollutants. Some of the ramifications of emerging pollutants, as illustrated by pharmaceuticals and personal care products, with regard to ecological and human health issues, are discussed in Daughton (2003a, 2003b).

The diminishing quantity and quality of potable source waters is a pressure that heightens interest in water reuse. Just as with treatment of waste waters for discharge to surface waters, the long-practiced purposeful recharge of ground water (both indirect and direct) is a major route to achieving water reuse, but is also being impacted by these new concerns regarding emerging pollutants. In this paper, I do not attempt to cover the countless science issues associated with the removal of pollutants from water destined for use in recharge. Nor do I discuss the risks that may be associated with trace levels of emerging pollutants in ground water; many of those issues are covered in Daughton (2003a, 2003b). For the public, the long latency of disease onset that can be associated with exposure to chemical stressors makes assumption of risk much more difficult to accept. Even the waterborne microbial risks occur on a much shorter time horizon. Delayed onset and rare diseases can escape detection, even by exhaustive epidemiological studies (e.g., simply because of the transient nature of most communities and because such studies are fraught with problems related to statistical power because of wide natural variations).

I will, instead, discuss some alternative perspectives on why much confusion and divisiveness sometimes exist among water reuse stakeholders and the public, and how the existing science could perhaps be better communicated with the ultimate desired outcome being that consumers are best informed to make not necessarily more rational decisions regarding water reuse, but to make the decisions necessary to sustain the living standards that optimally reflect their value system.

\section{Background}

\section{Interfaces: The Complex Origin of \\ Many Unknowns and Much Confusion}

Ground water recharge excels at highlighting the central role of interfaces, the connections and collisions of two vastly disparate worlds-the surface and subsurface. Extraordinary contrasts abound in these two worlds-aerobic vs. anoxic, young vs. old water, the place where the end of the water cycle can be said to rejoin with its beginning, where the overt prevalence of macroorganisms yields to the dominance of invisible microbial processes, where contamination can be removed by natural purification, a world that can be understood in large part by the visual senses vs. one that resists comprehension by any of the senses, and, finally, where science (and reality) can clash with the public (and perception). It is the latter on which this paper focuses, the collision of what scientists posit as reality with what the public can perceive with skepticism. The science-public interface is one that often presents itself as a perplexing chasm when dealing with the communication of hazard and risk.

The major focus of this paper is the interface between science and the public-an ever-changing, confusing, and sometimes controversial arena that many scientists prefer to avoid as it pertains to water recharge and reuse.

Interfaces at the junctures of the dissimilar offer boundless complexity and formidable challenges to examination and discovery. Interfaces are also where things happen and, therefore, prove critical to everything from the transport of nutrients and communication of chemical signals across cell membranes to the transport and fate of chemicals across environmental compartments to the communication of ideas between disparate science disciplines. Scientists have long appreciated the critical importance of understanding the complex processes that occur at interfaces. Unfortunately, such challenging territory is usually avoided in public discussion.

Innumerable debates refractory to resolution reside in the environmental sciences-some among scientists (or disciplines) and others between scientists and the public. One in particular involves the wisdom of using treated human waste water to recharge ground water aquifers. The capabilities of advanced waste water treatment technology (at least on paper) offer the potential to cost-effectively produce water whose purity exceeds that of highly prized pristine natural water sources; water treated to such high standards is sometimes called repurified. This capability could provide many geographic locales facing ever-diminishing fresh water resources the wherewithal to control their own water cycle, effectively ensuring a sustainable water supply for all where increasing water demand and usage could be automatically balanced by increased water recycling.

What seems so straightforward on paper, however, possesses other dimensions that can transcend what is often assumed to be common sense. A large number of obstacles often block the practical implementation of ground water recharge, especially when it is perceived as the first step toward being ultimately used for drinking. These obstacles derive from scientific, technological, political, and sociopsychological concerns, and are driven by a diverse array of agendas. In the final analysis, regardless of how safe recycled water can be made (and proven to be made), all that matters is whether the public will embrace it. In communicating risk, perception is reality. When technology advances faster than society can formulate mental pictures for its acceptance (or guidance or regulatory frameworks for its control), the public can reject the technology, regardless of its purported or proven advantages. This is borne out by the revolution in genetically engineered (modified) organisms and how its advancements rapidly evolved before guidance and controls acceptable to the public could be formulated. Technology in absence of controls can catalyze mistrust and fear (witness instances of food-poor countries shunning the opportunity of plentiful food made possible by genetic engineering) that then require investment of inordinate time (that need not have been required) to bring the debate back to a manageable starting point.

Indeed, although belief (or superstition) is not only a significant factor in the way the public responds to perceived risks, belief in, or suggestion of, phantom risks can elicit 
actual adverse health effects. Known as the nocebo response, the term nocebo started to become common in the $1990 \mathrm{~s}$ when it was noted that patients' expectations of adverse drug effects could significantly influence treatment outcomes. The nocebo effect (the opposite of the placebo effect) is a real, physiological adverse outcome caused simply by the suggestion or belief that something (such as a chemical) is harmful, regardless of any inherent toxicity (Daughton 2002). The nocebo effect could play a key role in the development of adverse health consequences from exposure even to trace levels of contaminants simply by the power of suggestion. The nocebo effect shows that real health effects can result from an errant perception of hazard.

The determinants of risk and how they are formulated, perceived, and valued by society are among the most important issues surrounding water reuse and therefore have direct bearing on the implementation of ground water recharge. Moreover, what science knows today may be woefully insufficient tomorrow. Ground water recharge of treated sewage could incur large liabilities not foreseeable today if years from now problems are discovered or suspected regarding the failure to reject from waters low levels of previously unrecognized solutes known to pose either real or perceived risks. For this reason, lessons learned from experience with the precautionary principle (Daughton 2003c) should be studied and understood with regard to the design of ground water recharge programs. After all, even reverse osmosis is only partially effective at removing low molecular weight solutes (certain acids and neutrals) $<500$ daltons (Drewes et al. 2003), a range occupied by many potential pollutants.

\section{Risk: The Faces of Perception and}

Reality in the Psychology of Society

The chasm separating how experts measure, characterize, or assess hazards and how the public prioritizes, ranks, or perceives risks is well known. The many and disparate means that formulate risk by experts, individuals, and societies can make this a difficult issue to address.

Hazard can be defined as the quantifiable probability of an adverse event such as injury, damage, or loss. However, the public does not relate to the purportedly objective, measurable concept of hazard as much as it does to how risk is sensed by subjective feelings - a process often laden with strong forces resulting from many complex aspects of emotion, mores, values, beliefs, ethics (e.g., environmental justice concerns), valuations, ideologies, superstitions, lifestyles, expectations, motivations (e.g., water availability encourages population growth), preferences, and attitudes. These forces are a complex and widely varying function of culture, family, race, ethnicity, religion, gender, age, social status, education, indigenous knowledge, political beliefs, feelings, etc. Communities with high social/cultural diversity face the greatest challenges in agreeing on what constitutes hazard. Further complicating the matter is that these factors can vary among individuals of any group, many cannot be foreseen or anticipated, and all can seem (from the perspective of scientists) to be divorced from logic, yet are very real to the person sensing the risk.

A profound disconnect therefore exists in the way risk assessors define hazard and in the way that the public per- ceives risk. While the two sides often are deluded into thinking they are indeed communicating about the same given issue, they actually devolve from completely different, and seemingly irreconcilable, frames of perspective (Slovic 2001). Perceived risks (as formulated by the public) are often judged as irrational by scientists. The public, on the other hand, often views science as continually revisiting the same unimportant issues and being mired in a paradoxical mix of endless detail, vagary, and often-contradictory conclusions and recommendations. Making everything even more confusing and frustrating, the advancement of knowledge regarding contentious issues laced with perceived risk often will sometimes not assuage the concerns of the public, but instead serve to exacerbate their concerns (Slovic 2000). Regardless of how difficult to explain the differences between the two perspectives, they are very real nonetheless.

Although improved science literacy (Daughton 2003d) might be in part necessary for the public's appreciation and perception of science, it is not sufficient for aligning the disparate views of risks as held by scientists and the public as there are many other factors not related to science that the public uses in developing its collective sense of risk, and which are at least as important as scientific facts. Some are as simple as conflicting lexicons, as pointed out by the example used by Yankelovich (2003) with the opposite interpretations of what constitutes a theory, where the public views a theory as equivalent to what scientists refer to as an untested hypothesis.

Real hazard contrasts sharply with perceived risk. These are two different constructs requiring completely different strategies to effectively communicate them to the public. Regardless of how sound the science may be, its influence on the perception of risk may be minimal. The formulation of perceived risk by the public inexorably evolves with, or without, the prior development of an adequate scientific basis.

In large part, it is irrelevant that perceptions do not necessarily correlate with reality. This can be easily understood by analogy with the stock or real estate markets. The value of a commodity is often determined not by its inherent value (analogous in this example to real hazard), but rather by how people (investors) happen to perceive its value at any point in time (analogous in this example to risk perception), which may be diametrically opposed to the reality as measured by experts (e.g., market analysts). Continuing with this analogy, the propensity of the public to fixate on a topic of supposedly trivial or untrue nature is what makes possible speculative bubbles (as well as other historical events of mass delusion often in distinct opposition to self-interest [MacKay 1841]) and, at the same time, sets the stage for inevitably ensuing market downfalls (e.g., the phenomenon of social amplification of risk [Kasperson et al. 1988]).

At the same time, the public is capable of disengaging its concern for issues that are measured as representing real and significant hazards (e.g., driving automobiles, cigarette smoking, poor nutrition, imprudent use of antibiotics). Regardless of the inherent monetary or psychological value of something, all that matters in the final analysis is how it is valued by a buyer (investor). The value as deemed by the seller is irrelevant. The fact that market history is riddled with instances of truly superior products failing to win the hearts 
of consumers while inferior competitors flourish is testament to the power of perceived value and the sometimes inferior influence of demonstrated, objective data. The wide-ranging influence and historic importance of mass psychology are brilliantly recounted in the historic work by MacKay (1841), who compiled numerous examples of society's willingness to delude itself in ways completely contrary to its own selfinterest.

A major difference between an expert's assessment of actual hazard and the public's perception of risk is that the former is necessarily performed in the absence of complete objective knowledge (a characteristic of the nature of science) while the latter is developed in the presence of subjective, emotional values and instincts. Furthermore, science often must dwell on the development of negative data-documentation of absence. Nevertheless, the absence of something can never be proven, and even then, the absence of evidence is not evidence of absence. This point is particularly germane to communicating the risks associated with chemical pollutants in water at concentration levels below those causing any known effects, and which are often present at concentrations below those that can even be reliably detected by advanced chemical analysis.

Slovic (2001) maintains, ". . . because evidence for lack of risk often carries little weight, risk-assessment studies tend to increase perceived risk." The more studies that show the lack of an association between a cause and a purported effect, the more likely it is that such studies will exacerbate risk perception, and consequently increase public concern.

The topic of risk perception is integral to most discussions of unregulated/emerging pollutants. This area truly resides at the interface of science and policy, an interface that often becomes a cauldron of heated opinion and emotion, and effectively repels the participation of many scientists. The science of hazard assessment exists separately from the politics and policy often involved in the development of how risk is perceived. The two often seem to blur together, but in reality perhaps only seldom meet on common ground. This topic becomes particularly problematic when the public wants to know the significance of the oft-reported absence of findings or less frequent findings of absence-two common outcomes of research on the potential for health or ecological effects associated with long-term exposure to low levels of unregulated pollutants. While a comprehensive body of experience and knowledge has been developed with respect to communicating risks to the public regarding regulated chemical hazards, little experience exists with nonregulated pollutants or with those aspects of chemical exposure that reside outside the domain of conventional toxicology (e.g., long-term, simultaneous exposure to multiple chemicals each present at a level below that known to cause known effects) (Daughton 2003a, 2003e).

For particularly insightful discussions of the many faces of risk and how it is perceived by scientists and the public, see Gigerenzer (2002), psci-com.ac.uk (2003), and Slovic (2000, 2001) and Slovic and Weber (2002). Access to many other materials on risk assessment can be found at the Society for Risk Analysis' Risk Communication On-line Resources at www.sra.org/rcsg/rcsgsources.html and at the
U.S. EPA's National Center for Environmental Assessment at http://ctpub.epa.gov/ncea.

\section{Improving the Communication of Science and Risk- Is There a Psychologist in the House?}

Much has been written regarding the importance of communicating science to the public and efforts to improve what is often purported to be a closely allied problem - a decline in society's science literacy (Daughton 2003d). However, an extraordinarily important communication topic that receives comparatively short shrift by most environmental scientists is that of involving risk-a subject that plays a major role in dictating the many aspects of the conduct of daily life, as well as the overall cost of goods and services. Society's assessment of risk is intimately involved with setting its relative priorities. Science illiteracy is frequently assumed to be the origin for what scientists see as the public's unscientific perception of risk.

On the surface, it would seem that the objective, factual translation of what we know (and don't know) about the ecological and human health risks posed by environmental stressors (for example, as contaminants introduced to ground water for water reuse purposes) into a clear message for the public would end our public communication obligations. Unfortunately, the history of risk communication is fraught with so many difficulties that the message intended to be communicated often becomes garbled or translated to its opposite meaning at the science-public interface.

This failed translation process is often viewed by scientists as resulting from a public's science illiteracy, but a major factor confounding effective risk communication is the traditional, abstruse manner in which data are statistically distilled (e.g., the use of probabilities instead of more easily comprehended natural frequencies) where even experts can be completely stymied by statistical innumeracy (Gigerenzer 2002). Another factor is the failure to recognize the illusion of certainty and appreciate that only those uncertainties that can be expressed with statistically meaningful numbers can be referred to truly as risks, and, further, that risks need not be associated with adverse outcomes (Gigerenzer 2002). The critical importance to sustaining an informed public by clearly communicating through statistics was embodied in a comment attributed to H.G. Wells by Campbell (1974): "Statistical thinking will one day be as necessary for efficient citizenship as the ability to read and write."

However, even in a perfect world, a direct linkage between knowledge (in this case science literacy) and acceptance of risk would not necessarily exist. With science literacy aside, the failure to communicate risk might often originate from the unsuspected use of the wrong communication interface. Scientists try to communicate an objective reflection of a factual reality (or at least what little is known)-the facts and nothing but the facts. The public, however, does not necessarily judge or evaluate those facts through the same interface.

While the means for communicating with the public and involving them as stakeholders in environmental decisionmaking has received tremendous attention over the years (Karl and Turner 2003; SPIDR 1997; U.S. EPA 1990, 2001a, 2003) resulting in ever more refined approaches to public 
engagement, an obvious oversight has been the failure to employ those who might best function at the science-public communication interface. The best example is the underuse of experts from any of the specialty areas such as social, cognitive, cultural, or anthropological psychology, or even the nascent field of ecopsychology (which deals largely with sustainability issues). For example, the author of the book serving as the foundation of ecopsychology, Theodore Roszak, comments in an interview, "One of the ironies is that psychologists have been hired in great numbers to help people consume more. Why can't we enlist some of them on the other side of the issue, to speak out in defense on the natural environment?" (www.adbusters.org/magazine/30/ecopsychol ogy/3.html). Extending Roszak's comment, perhaps a more important question is why psychologists are not being engaged to serve as translators at the science-public interface and help bridge the communication chasm between the hazards identified by science and the public perception of risk.

While community involvement and public education are frequently recommended as the most effective means for changing perceptions, the way in which this is done is also critical and not necessarily well defined. For example, the public must be considered by water purveyors not solely as consumers, but also as partners. A discussion of this topic would take us into the processes being used more frequently by organizations for increasing their efficiency, relevancy, and impact. Two such approaches involve what are referred to as the logic model for planning and the principles behind the high performing organization for improving organizational effectiveness (Daughton, in press). An example of the latter, as applied to community involvement with water recycling, is presented in Stenekes et al. (2001).

Although the cognitive sciences and the social sciences have traditionally played a small, but growing, role in the characterization and communication of risks, the practitioners of these disciplines have played surprisingly and disappointingly insignificant roles at the interface of the public and science. Why are not psychologists or social scientists actively engaged more frequently as risk communication professionals to serve as translators across the interface? Those few who are actively engaged at the interface of science and the public need to publicize their involvement to the environmental science community, especially lessons learned and successes. This interface between science and the public is an uncomfortable place for most scientists, and for this reason, few scientists venture forth without trepidation. This may be the reason that progress has been so slow in this critically important front.

With a vigorous dialogue between science and the public, society's overall rankings of risks might very well change (perhaps better aligning with known hazard), thereby freeing valuable resources to devote to the most highly valued societal issues. A productive dialogue could also create a positive feedback loop, where science becomes more valued and, therefore, receives more political support and resources. Given the critical role that risk perception plays in setting society's values and guiding where our resources are directed, this dialogue needs to become an integral part of social discourse. Those science disciplines or subdisciplines unable to communicate their value, significance, or essence to society could eventually lose public respect or trust, and eventually fall victim to budgetary shortfalls (Daughton 2001a).

\section{A Potential Source of Public Confusion- An Incomplete Picture of the Water Cycle}

Although unplanned (unintended) indirect potable reuse has always occurred whenever waste water treatment plants discharge to ground waters (e.g., via land application) or surface waters serve as drinking water sources for downstream communities, the public evaluates risk differently if the reuse is perceived as resulting from planned (purposeful) mixing of the same treated waste water with water known to be destined for drinking, such as occurs with ground water recharge. The processes used by individuals in subconsciously developing their personal allotment or target level of risk (that degree of total, combined risk that each person actively seeks, or passively accepts or tolerates) continually operate in regulating their fixed level of total tolerable risk at a homeostasis point (Wilde 2001). History suggests that these allotments differ for unplanned and planned ground water recharge, as the public often will not accept reliance on existing, proven drinking water standards for planned recharge whereas they have long done so for unplanned reuse.

The public's formulation of acceptable risk regarding water pollution is inevitably intertwined with its understanding of the water cycle, an understanding that started to become formalized beginning in the 1600s (Gioda 1998). Society's current everyday knowledge that individual water molecules have distinct identities is captured in the refrain from satirist/songwriter Tom Lehrer's "Pollution," which quips, "The breakfast garbage that you throw into the Bay, They drink at lunch in San Jose" (http://members.aol.com/ quentncree/lehrer/pollutio.htm); alternate lyrics are "Throw out your breakfast garbage and I have got a hunch, that the folks downstream will drink it for lunch," "The breakfast garbage they throw out in Troy, they drink at lunch in Perth Amboy."

Such sentiment regarding the cycling of water reflects strong public emotions, which could even prove critical in determining the course of societal development. The public's understanding of water chemistry and the water cycle are reflected in proclamations such as "Lips that touch reclaimed water,' say Hahn and anxious homeowner association presidents, "must never touch mine." This quotation is attributed to Los Angeles Mayor James K. Hahn (Waldie 2002).

The public's level of psychological discomfort regarding the types of use for which recycled water can be employed is undoubtedly related to the hydrologic distance between the water's origin as waste and its use for personal activities (especially drinking), as well as to the number of natural or artificial barriers (processes that remove contaminants) existing along the way. Although the public might commonly relate to the often cited common knowledge (which is not technically correct) that all water readily accessible for human consumption has already undergone (and will forever undergo) repeated, perpetual excretion and reuse by myriads of organisms (Waldie 2002), it is the spatial and temporal proximity of the reuse that causes concern. Historically, the 
hydrologic connection between fecal and urine wastes and drinking water has been so distant or so subtle that few people gave it much thought.

Public surveys continually show that anxiety increases as the hydrologic connection is made more obvious and shortened between the time aqueous waste is excreted and the time its water component is reclaimed and reintroduced to potable water supplies regardless of the absence of real hazard. The degree of comfort seems to increase as a function of the time that water has aged or traveled-the more remote the hydrologic connection, the easier it is for the public to accept water reuse. Recharge of ground water with purified water generated from advanced treatment of human waste water represents one end of the spectrum of hydraulic closeness (in both space and time), while direct toilet-to-tap programs (ultimately within an individual residence) sit at the other end of what has been referred to as the spectrum of "increasingly smaller recycle loops" (Asano 2001).

This is one of the reasons that ground water recharge is appealing for promoting water reuse-it introduces a delay factor. Nevertheless, this needed degree of hydrologic remoteness may simply reflect a lack of understanding as to what water really is and what the water cycle truly involves. Contrary to common teaching, water is not a conserved substance comprising distinct unchangeable molecules. Nor do individual, distinct molecules necessarily progress unchanged through what we call the water cycle. Much of the public's confusion results from contradictory statements such as "water is a finite resource" (with the obvious implications that we are at risk of using it up), while at the same time "water progresses through a never-ending cycle" (with the implication that it is continually replenished).

After a long learning curve, public outreach is now identified as a priority by most government agencies dealing with water reuse. Science education is often highlighted as a major need, and teaching of the water cycle is sometimes highlighted as one of those needs. Accurately communicating the science associated with the water cycle, however, seems to be fraught with difficulty as even scientists have trouble accurately articulating its basic principles and in capitalizing on those aspects of the water cycle that have direct bearing on how the public forms logical and emotional connections with water. After all, one of the key aspects of water reuse that the public has historically rejected is potable reuse whether direct or indirect. Even if reused water could be demonstrated to be purer (however that might be defined) than the best of natural, pristine waters, such recycled water would still be cited by many as somehow being tainted by its past. The following discussion focuses on several shortcomings in how the water cycle is taught. These shortcomings surround the misperception that water is an immutable chemical, a misperception that probably derives fallaciously from Lavoisier's law of conservation of mass.

Public rejection of the direct (purposeful) recycling of sewage, especially for drinking water, sometimes derives from incorrect understandings of basic science. For example, public rejection sometimes stems from the perception that the actual water molecule is somehow tainted by its origin from waste - that water molecules can somehow carry a memory of their history. This misconception perhaps results from the inaccurate communication of science. When scientists speak of contaminated water, they do not actually mean that the molecules themselves have been physically altered. After all, except for reactions with nonwater molecules and the ongoing ionization/equilibrium processes and the three-dimensional structures that bulk assemblages of water molecules assume, the absolute physical structure of water molecules remains unchanged in the presence of contaminants. What we actually mean by contaminated water is that it harbors molecules of other (nonwater) types of substances (solutes) from the universe of chemicals. Once these intermingled contaminants are removed, the remaining bulk water is compositionally identical to the original pristine water-the individual water molecules are indistinguishable from one another, and perhaps more importantly, these water molecules have no memory of the contaminants to which they had been exposed. There are absolutely no lasting or even ephemeral effects from prior contact with the contaminants. Of course this line of reasoning presupposes the absence of the controversy that has long surrounded homeopathy and the hydrogen-bonding memory that can be purportedly maintained by water - a controversy that is periodically renewed (Rey 2003).

For scientists, the view that water can retain some sort of association or memory of its past - much like dirty moneydoes not reflect reality or logic. Nevertheless, an examination of how the water cycle is taught can reveal that this perspective is fostered through the very way in which the water cycle is oversimplified and perhaps even misunderstood by scientists themselves. As a further example, let's start with a statement often made with regard to the world's water supply: "Water is a finite resource. There is no such thing as 'new" water." (State of California 2003).

This statement, whose intent might be understood by scientists, perpetuates two common misconceptions - first, the amount of water on earth is an absolute constant, and second, water is immutable, i.e., new water cannot be created. These two seemingly trivial misstatements may lie at the root of the public's view that water can be tainted or stained by its past, and they therefore could have profound ramifications regarding the public's acceptance of water reuse. With emphatic statements such as the nonexistence or impossibility of new water, the consumer can only conclude that all water is olda connotation that clearly holds the potential for harboring stigma.

By taking a few steps back and reexamining certain overlooked, fundamental aspects of water chemistry and the water cycle, we can gain an extraordinarily important perspective on where science has led the public (and perhaps itself) astray. Although comprising an extremely simple but life-essential molecule, bulk water is actually a complex, dynamic chemical entity that undergoes continual reactions and interactions among individual molecules. Water molecules constantly undergo ephemeral associations with each other (e.g., via networks of clusters) and with other molecules, followed by equally ephemeral dissociation. In this dynamic process, molecules acting as acceptors or receptors exchange protons. This continual breaking and reforming of weak hydrogen bonds does indeed result in the creation of new water molecules in the sense that these individual molecules 
comprise different specific atoms of oxygen and hydrogen resulting from the continual exchange of protons. Indeed, it perhaps makes little sense to envision individually distinct water molecules as ever progressing even partway through the water cycle intact. Bulk water can therefore be viewed as a continuous chemical entity, undergoing dynamic disassembly and rearrangement rather than a liquid of distinct, immutable molecules. In this sense, water could be viewed as undergoing a continual, natural process of self-rejuvenation-a distinction with possibly profound ramifications for perception of risk. At the same time, however, we need to appreciate the difficulty in clearly communicating science as exemplified here. On the one hand, we can state that water (namely its molecules) is ceaselessly changing (in terms of the specific atoms its constituent molecules comprise), and, at the same time, water never changes (in terms of its fundamental structure, or atomic composition). This could seem like a paradox to a nonchemist if not presented properly.

Another issue regarding the misconception that there is no such thing as new water is that water (in terms of distinct molecules) is indeed being continually created and consumed (destroyed) in a wide array of chemical reactions. Such reactions include, among others, the myriads of common anabolic and catabolic processes in all living organisms. Perhaps confused with the conservation of mass, the amount of water (like all molecules) is not conserved, but rather undergoes a dynamic fluctuation, albeit perhaps imperceptibly. We could more accurately state that the world's amount of water is more or less at quasi-equilibrium, with new water molecules continually being created (as products of chemical reactions) and existing ones being continually consumed (as reactants), but these two opposing processes are not linked. The water cycle as taught today omits these fundamental major aspects-continual renewal and destruction-and thereby leads the public to formulate an aberrant archetype model of water. This misunderstanding even leads some to believe that water molecules are immutable and that these molecules have origins as distinct individuals traceable back through the millennia (Waldie 2002).

A more realistic archetype of water, one where individual molecules are not immutable, and where entire molecules are continually destroyed and created, could have profound implications for how the public perceives water as having origins directly from the excrement of others. After all, if the structure of water molecules is continually changing (as a result of both intermolecular rearrangements, and as a result of creation and destruction of distinct water molecules by natural processes), then the water cannot be viewed as retaining any imprint of its origin. This more realistic archetype of water could engender a philosophy whereby water is viewed as self-regenerating, readily capable of losing any perceived taint or imprint from prior association with dirty processes. With the help of advanced technologies for removal of contaminants, the ability of water to regenerate could be viewed as revitalization or rejuvenation, thereby facilitating its healthy reuse. Moreover, the public responds favorably to the idea of natural purification of water as opposed to artificial cleansing processes.

While this alternative view might first strike some as a snake-oil approach, if these rather boring water chemistry facts could be translated into a more accurate and engaging picture of what water really is and isn't, the public might gain a better understanding of the water cycle and how it relates to water reuse. As an attempt at translating a highly complex process (exposure of organisms to stressors) to a picture format more suited to engaging the public, the cartoon illustration of Daughton (2003e) is offered as an example.

Improving public communication might also benefit from a new lexicon, one that greatly simplifies and clarifies the existing proliferation of terms (often loosely used with different meanings) for describing the treatment of municipal waste water for purposes other than direct discharge to surface waters. This lexicon could capitalize on the alternative view of water discussed previously. These existing terms only add to public confusion-waste water that has been reclaimed, reused, recycled, or repurified, and then further obfuscated with modifiers such as unplanned vs. planned, indirect vs. direct, or potable vs. nonpotable. The combinations and permutations can be mind numbing to the public. Different combinations sometimes have the same meaning, other times not. Paradoxically, perhaps this cacophony of terms could be countered with the introduction of newer terms that could rectify multiple existing problems concerning understanding and perception. As examples, consider regeneration, renewal, revival, rejuvenation, or revitalization. These terms could convey the fact that water is not simply being reused (with its obvious connotation of being old), but that it has also been subjected to a process that returns it to its natural state, making it suitable for drinking-compatible with sustaining health and vitality.

The power of metaphor should also not be discounted where analogies might be used to conjure positive mental pictures, especially to replace established negative images. Here's an example that could be used to promote a better understanding of recycled water. Consider the analogy between the filtration of contaminated water by reverse osmosis (RO) and the continual life-sustaining process used by our own cells - transmembrane aquaporins - that facilitate the exquisitely selective entry of water molecules and reject all other molecules, including even the hydronium ion. In this metaphor, RO does what our bodies are already continually engaged in naturally.

\section{Other Aspects of the Water Cycle Relevant to Water Reuse}

Many other little-discussed aspects of water chemistry also have direct bearing on the public's understanding of processes involving water and could prove important to teach. For example, water is essentially impossible to prepare in an absolute pure form (i.e., solely comprising molecules of water with absolutely no contaminants). Because of its aggressive solvent nature (water is often termed the universal solvent), the storage of pure water is even more difficult to achieve because it immediately acquires (dissolves) myriads of contaminants (solutes) from its surroundings, even from inert storage containers. This conveys the fact that purity is always a matter of degree of contamination and, as the capabilities of analytical chemistry improve (its ability to detect new contaminants expanded, and the detection limits for existing chemicals lowered), we might approach that hypothetical point where any chemical can be detected anywhere 
(Daughton 2003b, 2003f). Furthermore, with regard to the use of highly pure water for drinking, its correlation with improved human health is controversial because pure water may have a greater ability to leach toxic metals from distribution lines, serving and storage containers, and dental amalgams, as well as essential minerals from the body. Natural sources of water with their suites of minerals unaltered may serve as an important source of essential trace minerals for certain subpopulations. The message is that the public needs to know that water of increasing purity is not necessarily a positive with regard to health.

The issue of purity is also interrelated with that of hormesis, a subject long controversial among toxicologists. Simply put, evidence that continues to be mined from the existing literature (Calabrese and Baldwin 2003; BELLE 2003) reveals that dose-response profiles for many stressor-exposed organisms often display paradoxical (U- or J-shaped) curves - a phenomenon where inhibition at higher doses is transformed to a stimulatory response at low doses (a biphasic doseresponse). The significance of hormesis in this discussion is that the public's desire for water of ever-greater purity might be misguided in that chemicals at concentrations well below those currently believed or known to be inconsequential (e.g., the no-observed effect level) may indeed be able to elicit other effects that are unique to such low concentrationswhether these effects are deleterious is debatable.

Despite the fact that more data or more knowledge does not necessarily translate into public acceptance of what was previously considered a risk, in the case of unregulated water pollutants, an argument can be made for performing comprehensive chemical characterization of treated waters. By routinely demonstrating the omnipresence of a plethora of chemicals in all waters, regardless of source, perhaps the public could gain a better appreciation that the occurrence of trace chemicals in water supplies is a ubiquitous phenomenon and one that can never be avoided or eliminated. Eventually, perhaps success could be achieved in the public's acceptance that these chemicals will forever constitute an inescapable background in our everyday lives.

Comprehensive chemical characterization of water supplies (while not currently possible in an exhaustive mannerfor example, mass-balance accounting for all organic carbon in terms of individual, identifiable organic contaminants) would normally be shunned by water providers as it is costly, extraordinarily time-consuming, and viewed by risk managers as prompting yet additional onerous and largely unanswerable questions with regard to communication of risk. What are the ramifications of revealing trace levels of substances for which little or no toxicological information exists? How clean is clean? How clean is safe? But the alternative, to ignore monitoring for those chemicals known to be present, but lacking useful toxicological information, could also be viewed as running counter to the precautionary principle (Daughton 2003c).

Two other major reasons exist for developing the capability to establish and monitor comprehensive lists and concentrations of contaminants in water destined for recharge. One is to select signature suites to measure in recycled water, not because they necessarily have anything to do with toxicity, but rather as quality assurance measures. Setting control limits around an appropriately extensive list that serves to trigger corrective actions when the limits are exceeded would be a major means of establishing and maintaining public trust in any water reuse system. It is not solely the performance (removal efficiencies) of treatment plants that is of concern, but also the sustained reliability of their performance (including the risk of failures). The second reason relates to the probability that the more complex an artificially enhanced water cycle becomes, the more vulnerable it could become to sabotage. For this reason, detection of any newly present contaminant in a timely manner could prove critical for water security.

\section{Other Suggestions for Enhancing Communication- Understanding the Outcomes Sought}

Experience shows that attempts at fostering active public participation in resolving controversial issues should use as many means as possible to engage attention and encourage interaction (meetings, focus groups, print media, and electronic media) because each imposes its own bias in attracting and selecting participants. As an example, although participation via the Internet is selectively limited by the digital divide (in contrast with physical meetings), individuals can participate whenever they like, for as long as they like, and as frequently as they like. The ultimate objective is to create an integrated system that allows for participatory equity given disparate social access to various communication mechanisms. One of the more recent methods that could be emulated by water districts planning recharge/reuse projects is the use of structured, moderated, online public forums. An example was the U.S. EPA's experiment with the National Dialogue that used electronic public participation (Beierle 2002; U.S. EPA 2001b).

Finally, while focusing on the method used for engaging the public and for fostering a collaborative learning process among all stakeholders, it is critical to not lose sight of the purpose for engagement. Although this might seem trivial, often all the parties involved do not share a common vision as to the outcome each seeks. The outcome sought must be understood from the beginning - always beginning with the end in mind (Daughton, in press). The consequence of overlooking this seemingly simplistic truism is that all ensuing efforts could have minimal impact, or worse- a counterproductive outcome. For this reason, the importance of using the logic model for planning and guiding all work cannot be overemphasized, nor can the need for employing the principles of high performing organizations (Daughton, in press). As a simple example pertinent to water recharge projects, the outcome sought might be acceptance by the consumer of water recharge for a variety of delineated end uses. Of critical importance, however, is whether the collective water consumers have clearly articulated what exactly would constitute acceptable water for their uses. If not, the end will always prove elusive.

Perhaps the ultimate measure for assessing the success of investing science and engineering resources in the development of technology for treating waste water for recharging ground water is not whether the technology can ever be proven safe, but rather that the public accepts it as efficacious and desirable. Society is rife with examples of technological 
advancements or practices that have been embraced by the public in spite of the fact that these innovations pose well documented, real hazards. Likewise, very safe and beneficial advancements are sometimes rejected by the public because of perceived risks (e.g., those who fear air travel).

\section{Beyond Ground Water Recharge-}

\section{The Future for Truly Decentralized Water Reuse}

The ultimate destination for our journey with water reuse, which begins with indirect water reuse (ground water recharge being a first step), is the completely decentralized (distributed) reuse of water at its very point of use, on-site. Pressure to pursue alternative waste treatment and drinking water sources will continue to mount not just because of growing drinking water shortfalls, but also because of the challenges and widening gap separating the current water centralized infrastructure network (at least in the United States) and the future to which it strives (U.S. EPA 2002). An advantage of distributed water reuse is its potential for lessening or avoiding some of the psychological barriers already discussed, but it could also solve some other problems, as well.

The potential for society's future migration from centralized municipal water treatment and distribution to one of truly distributed water reuse (where waste water is both treated and reused on-site, at its origin, such as within a home) poses unique questions regarding public acceptance, but also offers advantages regarding independence and the design advantage of inherent, ultimate security from sabotage. It is important to not confuse these on-site water recycling systems (which would use multiple stages of advanced treatment such as various levels of filtration [including RO], sorption, and oxidation) with conventional, rudimentary septic systems or leach fields.

Another advantage of truly recycling water generated directly from the domestic point of original use (as opposed to collective water from a multitude of domestic, municipal, and industrial generators) is that the universe of microcontaminants needing to be removed is vastly reduced. In particular, real or perceived concerns involving a wide array of toxic, exotic chemicals used by a large spectrum of industries (e.g., medical research and hospitals) and an even wider spectrum of chemicals used by the community of individuals residing outside each domestic residence would be completely avoided. Each residence would be concerned only with whatever chemicals are used on-site-certainly, a very small subset of those used communitywide. A transition period would also be possible, one where source water (for example, from recharged ground water) is provided by centralized purveyors and the final polishing to produce highquality water is done at the point of use or even by neighborhood facilities. After all, only a small fraction of household water is needed for drinking, bathing, or cooking.

A major concern with regard to the current impossibility of certifying that treated water is absolutely safe is the extraordinarily difficult, if not impossible, task of verifying that the treated water is free of any previously unrecognized contaminants. Perhaps the majority of all organic chemicals that compose the total organic load for any water are unknown or unidentifiable using current analytical technology (Daughton. 2003a, 2003b). This limitation of analytical chemistry is made particularly problematic given that the introduction to commerce of new and exotic chemicals is continually driven by ever-evolving advanced technologies. This means that it is simply not possible to certify that any water is completely free of all contaminants on a continual basis. It would definitely not be technologically possible to continually monitor for all possible contaminants.

Resistance to reuse of sewage for drinking water emanates in large part from the emotional level and could be largely reduced if not eliminated if the sewage was reused on-site, as this approach would avoid one of the largest elements of the unknown-namely, contamination from other people's sewage. Driven by self-interest, on-site reuse would also encourage individuals to modify their behaviors and actions to partly control the quality of their own sewage. A number of strategies (such as toilet design) already exist for reducing the types and quantities of unregulated pollutants introduced to sewage (Daughton 2003a). Another major selling point for on-site sewage reuse is that it could obviate much of the need for centralized sewage treatment and its consequent discharge of effluents (which meet lower standards than for drinking water) to surface waters, and it would also reduce the performance demands for ground water recharge by minimizing pollutant loads from centralized treatment works. Such fully distributed, decentralized systems could be designed and implemented by existing municipal water authorities in a manner transparent to the consumer; the performance of these systems could even be continually monitored remotely and the need for maintenance triggered when rigorous quality control levels are exceeded.

\section{Conclusions}

Regardless of whether scientists are ever able to quantify the true risks associated with ground water recharge (especially with respect to drinking reclaimed water-or perhaps we should call it revitalized or rejuvenated water), the public will eventually have to judge for itself whether the known and unknown hazards are acceptable risks. The existing, and perhaps widening, chasm between science and the psychology of society greatly complicates the communication of risk and ultimately the formulation of societal priorities. Scientists need to become more involved with developing better ways to communicate science and risk (Daughton 2001a; Daughton 2003d). More dedication toward gaining public acceptance of water reuse might prove to be a less costly route than interminable research on comprehensive chemical characterization, toxicology, and epidemiology-work that could be forever fated in asymptotically attempting to prove a negative. Paradoxically, the true work for science may not be in developing new science but in figuring out how to distill and effectively communicate the knowledge that already resides in the literature-a process termed literature forensics (Daughton 2001b).

The standard to which the public holds science in assessing risks associated with perceived hazards that are invisible to all senses (e.g., microcontaminants in sources of drinking water) is often much higher than most realize. This is perhaps 
a result not just of the complex way in which risks are perceived, but also because society feels a strong, innate obligation to protect the well-being of those not capable of exercising their own judgment (because of their age or state of mental faculties). At the same time, this standard can change dramatically from community to community, and the communication strategy that works for one may not work for another.

The attention that science often attracts from the public frequently derives from science's limitations rather than its achievements - absence of evidence, failures, and outright unfavorable findings - rather than from its successes or in never-ending strings of negative findings (evidence of absence), the latter of which are viewed as a liability rather than as an asset.

The importance of the presence of certain emerging pollutants (such as pharmaceuticals) even at minuscule levels in treated waters (such as those destined for recharge) may ultimately reside not solely or even necessarily in their toxicological attributes as environmental pollutants, but rather in the potential they offer in changing the way the public perceives risk and alters its behavior. While the real hazards associated with trace pollutants in the environment are unknown (absence of evidence), the degree to which the public identifies with this issue (and any perceived risk projected toward it) could serve to reorder our historic perceived risk priorities, better aligning them with the scientific realities of actual hazard priorities. As hypothetical examples, perhaps other forms of pollution resulting from personal actions, behaviors, and activities pose more significant risks such as indoor air pollution, urban runoff, or beaches contaminated with sewage.

Although risk is a major focus, at the same time, proper attention must also be devoted to the benefits of ground water recharge and water reuse; in contrast to risks, benefits can vary substantially between communities. A major determinant in the perception of risk includes the benefits that would accrue, benefits such as reducing a community's demand for fresh water from pristine natural sources, vulnerability to drought, construction of dams, land subsidence, and discharge of sewage effluent to surface waters, as well as the potential for obtaining water of a quality higher than would have been obtained by traditional upgrading of native water supplies (because recharged water might be subject to more stringent treatment requirements). These need to be accommodated in any communication strategy designed to enhance the public's chance of reaching truly informed decisions, a responsibility whose difficulty continually expands in increasingly technological societies, but which is essential for ensuring informed democracies.

Future approaches to setting regulatory standards or developing guidance for the quality of water intended for ground water recharge will need the ability to cope with continual advancement in analytical chemistry, especially the lowering of detection limits and the expansion in the type of chemicals that can be detected. As the known universe of chemical contaminants continually expands (Daughton 2003b, 2003f), the design of future approaches for monitoring would benefit immensely by being self-correcting. While the science issues associated with a continually expanding known universe of chemical stressors may, or may not, prove of concern regarding human health, they might prove more and more of an issue regarding public acceptance of water reuse.

Processes intended for treating sewage destined for ground water recharge require close scrutiny. Treatment of recharge waters to existing drinking water standards may not prove sufficient for the public. Science at any point in history can often find itself under intense scrutiny in the future regarding issues that were not foreseeable. If concerns were to emerge regarding the failure to have removed trace levels of previously unrecognized solutes eventually shown to pose real (or even perceived) risks, large liabilities could loom because ground water is a resource not amenable to simple, inexpensive remediation. Cases in point include methyl-tertbutyl ketone and perchlorate.

The ultimate value to the public in the fact that pollutants emanate from the combined actions and activities of individuals may well reside in heightening the public's awareness and understanding of the intimate, immediate, and inseparable connections that each and every individual has with the environment. A better understanding of cultural/social/cognitive psychology and the nascent field of ecopsychology and how this expertise can be better used in communicating at the science-public interface may well be the most important investment we can make in the field of ground water recharge for gaining widespread public acceptance. Toward this end, more effective and creative ways of communicating fundamental facets of environmental science (especially the water cycle and the nature of water) need to be implemented.

In the final analysis, the public's acceptance of recycled water may even prove to have little to do with science. In 2002, an advertising company (Adams Outdoor Advertising, South Carolina) wanted to demonstrate the power of outdoor advertising. Deciding to test market a mythical product that should have proved to be unmarketable-bottled drinking water made from sewage and dubbed Outhouse Springstheir resulting ad campaign (www.outhousesprings.com/ index.html) proved to be a tour-de-force in simplicity, imagery, and humor. The campaign was so effective that water was actually bottled (but not from sewage) bearing the Outhouse Springs label and placed in local markets to meet public demand.

Society's perplexing relationship with the paradoxical simplicity and complexity of water is reflected perhaps in no better way than by D.H. Lawrence's "The Third Thing" (Pansies, 1929).

$$
\begin{aligned}
& \text { Water is } \mathrm{H} 2 \mathrm{O} \\
& \text { Hydrogen two parts } \\
& \text { Oxygen one } \\
& \text { But there is also a third thing } \\
& \text { That makes it water. } \\
& \text { And nobody knows what that is. }
\end{aligned}
$$

\section{Acknowledgments}

The U.S. EPA, through its Office of Research and Development, funded and performed the research described. This manuscript has been subjected to the EPA's peer and administrative review and has been approved for publication. Men- 
tion of trade names or commercial products does not constitute endorsement or recommendation by EPA for use.

\section{References}

Asano, T. 2001. Water from (waste)water---The dependable water resource. 2001 Stockholm Water Prize Laureate Lecture; http://cee.engr.ucdavis.edu/faculty/asano/LaureateLectureFinal US.pdf.

Beierle, T.C. 2002. Democracy on-line: An evaluation of the National Dialogue on public involvement in EPA decisions. Washington, D.C.: Resources for the Future, 49-50; http://www.rff.org/Documents/RFF-RPT-demonline.pdf.

BELLE. 2003. Biological effects of low level exposures. Web site maintained by the BELLE Advisory Committee; http://www.belleonline.com.

Calabrese, E.J., and L.A. Baldwin. 2003. The hormetic doseresponse model is more common than the threshold model in toxicology. Toxicological Sciences 71 , no. 2 : 246-50.

Campbell, S.K. 1974. Flaws and Fallacies in Statistical Thinking. Englewood Cliffs, New Jersey: Prentice-Hall.

Daughton, C.G. 2001a. Emerging pollutants, and communicating the science of environmental chemistry and mass spectrometry: Pharmaceuticals in the environment. Journal of the American Society for Mass Spectrometry 12, no. 10: 1067-1076; http://epa.gov/nerlesd1/chemistry/pharma/images/book_jasma. pdf.

Daughton, C.G. 2001b. Literature forensics? Door to what was known but now forgotten. Environmental Forensics 4, no. 2: 277-282; http://epa.gov/nerlesd1/chemistry/forensics.htm.

Daughton, C.G., comp. 2002. The placebo and nocebo effects. U.S. EPA; http://epa.gov/nerlesd1/chemistry/ppcp/relevant.htm\#The PlaceboEffect.

Daughton, C.G. 2003a. Cradle-to-cradle stewardship of drugs for minimizing their environmental disposition while promoting human health, 1. Rationale for and avenues toward a green pharmacy. Environmental Health Perspectives 111, 757-774; http://ehpnet1.niehs.nih.gov/docs/2003/5947/abstract.html; http://epa.gov/nerlesd1/chemistry/ppcp/greenpharmacy.htm.

Daughton, C.G. 2003b, Non-regulated contaminants: Emerging issues. In Institute of Medicine of the National Academies Roundtable on Environmental Health Sciences, Research, and Medicine Workshop 5: From Source Water to Drinking Water: Emerging Challenges for Public Health, October 16, Washington, D.C.; http://epa.gov/nerlesd1/chemistry/ppcp/images/iom2003.pdf.

Daughton, C.G., comp. 2003c. The precautionary principle ("reverse onus"). U.S. EPA; http://epa.gov/nerlesd1/chemistry/ ppcp/relevant.htm\#ThePrecautionaryPrinciple.

Daughton, G.C., comp. 2003d. Communicating science \& science literacy. U.S. EPA; http://epa.gov/nerlesd1/chemistry/pharma/ comm.htm.

Daughton, C.G. 2003e. Biological systems and stressors. U.S. EPA; http//epa.gov/nerlesd1/chemistry/ppcp/stressors.htm.

Daughton, C.G. 2003f. Pollution from the combined activities, actions, and behaviors of the public: Pharmaceuticals and personal care products. NorCal SETAC News 14, no. 1: 5-15; http://epa.gov/nerlesd1/chemistry/pharma/overview.htm.

Daughton, C.G. In press. PPCPs in the environment: Future research-Beginning with the end always in mind. In Pharmaceuticals in the Environment: Sources, Fate, Effects and Risks, 2nd edition, ed. K. Kümmerer. United Kingdom: CPL Scientific Publishing Services Limited.
Drewes, J.E., M. Reinhard, and P. Fox. 2003. Comparing microfiltration-reverse osmosis and soil-aquifer treatment for indirect potable reuse of water. Water Research 37, no. 15: 3612-3621.

Gigerenzer, G. 2002. Calculated Risks: How To Know When Numbers Deceive You. New York: Simon \& Schuster.

Gioda, A. 1998. Short history of water. UNESCO; http://www.unesco.org.uy/phi/libros/histwater/tapa.html.

Higgins, J., J. Warnken, P.P. Sherman, and P.R. Teasdale. 2002. Survey of users and providers of recycled water: Quality concerns and directions for applied research. Water Research 36, no. 20: 5045-5056.

Karl, H.A., and C.E. Turner. 2003. Incorporating science into decision-making. Science 300, 1370; http://www.sciencemag.org/ cgi/content/full/300/5624/1370c.

Kasperson, R., O. Renn, P. Slovic, H. Brown, J. Emel, R. Gobie, J. Kasperson, and S. Ratick. 1988. The social amplification of risk: A conceptual framework. Risk Analysis 8, no. 2: 177-187.

MacKay, C. 1841. Memoirs of Extraordinary Popular Delusions and the Madness of Crowds. London: Richard Bentley; http://www.econlib.org/library/Mackay/macExContents.html.

National Research Council. 1998. Issues in potable reuse: The viability of augmenting drinking water supplies with reclaimed water. Committee to Evaluate the Viability of Augmenting Potable Water Supplies with Reclaimed Water, Water Science and Technology Board, Commission on Geosciences, Environment, and Resources, National Research Council, National Academy Press report; http://www.nap.edu/books/ 0309064163/ html.

psci-com.ac.uk. 2003. Risk perception. The Wellcome Trust, a gateway to public engagement with science; http:/psci-com. org.uk/browse/detail/0b8b9a5d2ea482e5c77e48040cc04alc. html (cross-references to risk, risk communication, sciencepublic opinion).

Rey, L. 2003. Thermoluminescence of ultra-high dilutions of lithium chloride and sodium chloride. Physica A: Statistical Mechanics and its Applications 323, 67-74.

Slovic, P. 2000. The Perception of Risk. Dulles, Virginia: Stylus Publishing LLC; http://styluspub.com/books/book4752.html.

Slovic, P. 2001. The risk game. Journal of Hazardous Materials 86, no. 1-3: 17-24.

Slovic, P., and E.U. Weber. 2002. Perception of risk posed by extreme events. Prepared for discussion at the Risk Management Strategies in an Uncertain World Conference, Palisades, New York, April 12-13; http://www.ldeo.columbia.edu/res/ pi/CHRR/Roundtable/slovic_wp.pdf.

SPIDR. 1997. Best practices for government agencies: Guidelines for using collaborative agreement-seeking processes. Report and recommendations of the SPIDR Environment/Public Disputes Sector Critical Issues Committee, Society of Professionals in Dispute Resolution, January; http://www.odrc.state.or. us/ppbest.htm.

State of California. 2003. Water recycling 2030. 2002 Recycled Water Task Force, Department of Water Resources, State of California, May; http://www.owue.water.ca.gov/recycle/docs/ TaskForceReport.htm from http://www.owue.water.ca.gov/ recycle/taskforce/taskforce.cfm.

Stenekes, N., A.I. Schäfer, and N. Ashbolt. 2001. Community involvement in water recycling-Issues and needs. Presented at Recent Advances in Water Recycling Technologies, Centre for Water and Waste Technologies, Brisbane, November 26, 113-124; http://www.cwwt.unsw.edu.au/membrane/Papers/ NyreeFIN.PDF; http://www.cwwt.unsw.edu.au/membrane/ Publications.htm.

U.S. Department of the Interior. 2003. Water 2025: Preventing crises and conflict in the west; http://www.doi.gov/water 2025. 
U.S. EPA. 1990. Sites for our solid waste: A guidebook for effective public involvement. Office of Solid Waste, Office of Policy, Planning, and Evaluation, U.S. Environmental Protection Agency; http://www.epa.gov/epaoswer/non-hw/muncpl/sites/toc.pdf.

U.S. EPA. 1992. Guidelines for water reuse. Office of Technology Transfer and Regulatory Support, U.S. Environmental Protection Agency, EPA/625/R-92/004; http://www.epa.gov/ordntrnt/ ORD/NRMRL/Pubs/625R92004/625R92004prel.pdf/;http://www. epa.gov/ORD/NRMRL/Pubs/625R92004/625R92004.htm.

U.S. EPA. 2001a. Stakeholder involvement and public participation at the U.S. EPA: Lessons learned, barriers, and innovative approaches. Office of Policy, Economics, and Innovation, U.S. Environmental Protection Agency, EPA-100-R-00-040; http://www.epa.gov/publicinvolvement/pdf/sipp.pdf.

U.S. EPA. 2001b. Public involvement in EPA decisions--The National Dialogue. Convened by the U.S. Environmental Protection Agency and hosted by Information Renaissance, July 10-20; http://www.network-democracy.org/epa-pip.

U.S. EPA 2002. The clean water and drinking water infrastructure gap analysis. Office of Water, U.S. Environmental Protection Agency, EPA-816-R-02-1020; http://www.epa.gov/owm/ gapreport. pdf.

U.S. EPA. 2003. Public involvement: Public participation requirements Web page. U.S. Environmental Protection Agency; http://www.epa.gov/publicinvolvement/public/; http://www. epa. gov/publicinvolvement/.

Waldie, D.J. 2002. Los Angeles' toilet-to-tap fear factor, Los Angeles Times, December 1; http://safewaterreuse.org/toilet_to_tap. htm.
Wilde, G.J.S. 2001. Target Risk 2: A New Psychology of Safety and Health. Toronto: PDE Publications; http://www.pde.drivers. com/store/books/014.php; http://pavlov.psyc.queensu.ca/target. Yankelovich, D. 2003. Winning greater influence for science. Issues in Science and Technology Summer; http://www. nap.edu/issues/19.4/yankelovich.html.

\section{Biographical Sketch}

Christian Daughton (http://epa.gov/nerlesdl/bios/ daughton.htm) oversees research at the U.S. Environmental Protection Agency on the environmental ramifications of chemical pollutants, with emphasis on the diverse class of emerging pollutants comprising pharmaceuticals and personal care products (http://epa.gov/nerlesd1/chemistry/ pharma/). Prior to joining the U.S. EPA, he was with the research toxicology faculty at U.C. Berkeley and a supervisory research scientist at Lawrence Berkeley Laboratory. With a B.A. in biology (U.C. San Diego, Revelle College) and a Ph.D. in ecology (U.C. Davis, Environmental Toxicology), he also served as an NIH postdoctoral fellow (Cornell University). He may be reached at Chief, Environmental Chemistry Branch, Environmental Sciences Division, National Exposure Research Laboratory, U.S. Environmental Protection Agency, Las Vegas, NV 89119; (702) 798-2207; fax (702) 798-2142; daughton.christian@epa.gov. 